\title{
Can fiat currencies really hedge Bitcoin? Evidence from dynamic short-term perspective
}

\author{
Jihed Majdoub ${ }^{1,2} \cdot$ Salim Ben Sassi ${ }^{1,2} \cdot$ Azza Bejaoui $^{1}$
}

Received: 26 December 2019 / Accepted: 23 November 2020 / Published online: 6 January 2021

(c) Associazione per la Matematica Applicata alle Scienze Economiche e Sociali (AMASES) 2021

\begin{abstract}
Whereas much research has largely investigated the safe haven, diversifier and hedge proprieties of cryptocurrency, very few papers have analyzed the hedging issue of cryptocurrency with other assets. As such, this paper attempts to investigate the possibility if Bitcoin can be hedged by selected fiat currencies (EUR, JPY and GBP) as Bitcoin prices have experienced high and persistent volatility. To do so, we compute optimal hedge ratios between Bitcoin and fiat currencies over the period 02/02/201230/11/2017 based on the VAR-DCC-GARCH model, VAR-ADCC-GARCH model and VAR-component GARCH-DCC model. A rolling window analysis is employed to establish out-of-sample one-step-ahead forecasts of dynamic conditional correlations between different assets. This leads to establish time-varying hedge ratios and thus dynamic cross-hedging Bitcoin/fiat currency markets. The empirical results clearly show the time-varying correlations between Bitcoin and fiat currencies under different specifications, implying a dynamic behavior of the relationship between such assets. For all the proposed models, such dynamic correlations are rather characterized by trending downward over the period under study. The results also display time-varying hedge ratios which lead to an ongoing regular demand for rebalancing the hedged positions under different specifications. As a matter of fact, using various models which take into account different aspects of volatility and correlation structures allows to better implement dynamic hedging strategies.
\end{abstract}

Keywords Bitcoin · Fiat currency $\cdot$ Hedging $\cdot$ Portfolio strategies $\cdot$ Dynamic perspective $\cdot$ Risk management $\cdot$ GARCH-type models

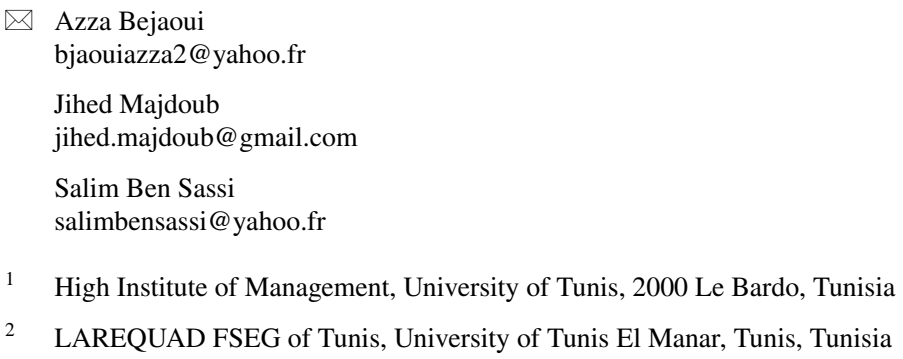


JEL Classification $\mathrm{G} 11 \cdot \mathrm{G} 15 \cdot \mathrm{C} 22$

\section{Introduction}

Overwhelmingly, cryptocurrencies have become a widespread and fascinating phenomenon which is eminently addressed by financial and governmental institutions as well as academic researchers. From a policy standpoint, digital currencies put forward a shift away from the established design of financial system infrastructures given their digital representation. They have interestingly soared in response to uncertainty surrounding the conventional economic and banking systems and the perceived failures of governments' central banks during crises (e.g., European debt crisis of 2010-2013). Obviously, the advent of such new currencies brings into play the functioning and stability of the financial systems.

From a research standpoint, the digital currencies drew tremendous interest in the financial literature and significant attempts have been made in exploring different issues. Undoubtedly, the first interesting question deals with the nature of Bitcoin, if Bitcoin can be considered as an alternative currency or speculative asset (or investment). Whereas a currency can be characterized as a unit of account, medium of exchange and store of value, an asset does not conspicuously have the two first ones and can be apparently disentangled (Baur et al. 2017). Therefore, if the Bitcoin is considered as an investment, it could compete with other assets (e.g., stocks and government bonds). Rather, if it is employed as a currency to pay for service or goods, it might compete with other fiat currency and influences central bank's monetary policies. Selgin (2015) and Baeck and Elbeck (2015), among others, assert that Bitcoin represents a speculative asset rather than a currency. Yermack (2013) reports that many features such as a lack of a central governance structure, cybersecurity risks, the diversity of Bitcoin prices among different exchanges and Bitcoin's comparatively low level of adoption hinder such cryptocurrency to be a currency. Using different data, Glaser et al. (2014) examined what users' intentions were when changing their domestic into a digital currency. They clearly show that the interest of new users affects the Bitcoin volume traded at the exchange but not on the volume within the Bitcoin system. This implies that exchange users purchasing Bitcoin seem to keep such digital currency in their wallet for speculation purposes but do not employ it for paying goods or services. They also show that Bitcoin returns react on news about this crytocurrency, again implying that users perceive Bitcoin as an alternative investment. As well, Baur et al. (2017) reveal that Bitcoin is primarily used as investment rather than being employed for transactions (i.e., a medium of exchange) due to its high volatility and returns.

By considering cryptocurrency as an asset, other researchers thereafter tried to investigate some empirical proprieties of cryptocurrency prices and in particular the volatility dynamics. For instance, Katsiampa (2017) attempted to estimate and explain the Bitcoin price volatility by comparing several competing GARCH-type models. The results clearly indicate that the AR-CGARCH model performs very well, implying the importance of having both short-run and long-run components of conditional variance. Chaim and Laurini (2018) used different specifications 
to apprehend the dynamics of daily Bitcoin returns and volatility. They reveal the importance of integrating permanent jumps to volatility. They also highlight the existence of two high volatility periods: the first one from late 2013 to early 2014 and the second one during the 2017 year. More recently, Ben Cheikh et al. (2019) investigated the asymmetric behavior of volatility in the major cryptocurrency markets (Bitcoin, Ethereum, Ripple and Litecoin) over the period 28/04/2013-01/12/2018. Using the Smooth Transition GARCH model, they show an inverted asymmetric reaction for the most of virtual currencies. In other words, good news tends to affect much more the volatility's behavior than bas news. Katsiampa (2019) examine the volatility dynamics of Bitcoin, Ethereum, Ripple, Litecoin and Stellar Lumen over the period 07/08/2015-10/02/2018. The empirical results display that the conditional variances of all the five digital currencies are significantly affected by past conditional volatility and previous squared errors. Also, asymmetric past shocks influence the current conditional volatility. The volatility dynamics of virtual currencies appear to be generally responsive to major news. Baur and Dimpfl (2019) analyze the asymmetric volatility effect for twenty cryptocurrencies. They show that positive shocks increase the volatility more than negative shocks. Such finding can be explained by the trading activity of uniformed investors (resp. informed investors) in the case of positive (resp. negative) shocks. Caporale and Zekokh (2019) search for the best (or set of) model(s) to model cryptocurrency price volatility based on different procedures (backtesting VaR and ES and Model Confidence Set procedure). They clearly display that employing classic GARCH models can lead to incorrect VaR and ES predictions and ineffective risk management, portfolio optimization and pricing of derivative securities.

In parallel, other researchers rather prefer to examine the role of cryptocurrencies from the perspective of investors. More explicitly, they investigate the safe haven, hedging and diversifying capabilities of Bitcoin given its weak negative or positive correlation with other assets. For instance, Dyhrberg (2015) analyzes the hedging ability of Bitcoin against stocks in the Financial Times Stock Exchange Index and the American dollar over the period 19/07/2010-22/05/2015. The results clearly display that Bitcoin is characterized by hedging capabilities against the FTSE Index. Bitcoin can be used as a hedge against the dollar in the short-term. Bouri et al. (2016a) show that Bitcoin has safe haven propriety over the pre-crash period. Such propriety nevertheless tends to vanish after the price crash of 2013. Bouri et al. (2017a, b) test if Bitcoin can hedge global uncertainty over the period 17/03/2011-07/01/2016. They clearly display that Bitcoin has hedging capability against uncertainty at the extreme ends of the Bitcoin market and global uncertainty at shorter investment horizons. Bouri et al. $(2017 \mathrm{a}, \mathrm{b})$ investigate the hedge and safe haven proprieties of Bitcoin against different assets (e.g., major world stock indices, bonds, gold and oil) over the period 07/2011-12/2015. They display that Bitcoin is poor hedge and can be considered as an effective diversifier for most of the cases. Otherwise, in a few cases, Bitcoin has hedge and safe haven proprieties which differ between horizons. Chan et al. (2018) investigate if Bitcoin can diversify and hedge risk against the Euro STOXX, Nikkei, Shanghai A-Share, S\&P500 and the TSX index in dynamic way. They indicate that Bitcoin is (resp. is not) an effective strong hedge for all the indices based on monthly (resp. daily and weekly) data frequency. 
Urquhart and Zhang (2019) examine if Bitcoin can act as hedge or safe haven against fiat currencies. They prove that Bitcoin plays a role of hedge (resp. diversifier) for the CHF, EUR and GBP (resp. AUD, CAD and JPY). They also show that Bitcoin is a safe haven for economic policy uncertainty.

From the aforementioned findings emerge two facts. First, Bitcoin presents high volatility and therefore can be considered as high risk investment. Second, the safe haven, hedge and diversifier proprieties of Bitcoin tend to vary according to data frequency, the nature of assets and methods. That is why Pal and Mitra (2019) instead seek to investigate the possibility of hedging Bitcoin prices with different assets (S\&P500, gold and wheat) over the period 03/01/2011-19/02/2018. They find that Bitcoin can be hedged with gold, wheat and S\&P500 based on different GARCH-type models (DCC-GARCH, GO-GARCH and ADCC-GARCH). Following Pal and Mitra (2019), we compute optimal hedge ratios between Bitcoin and fiat currencies in order to explore whether Bitcoin can be hedged by such assets and therefore potential hedging strategy might be well-established. From methodological standpoint, we employ VAR-DCC-GARCH model, VAR-ADCC-GARCH model and VAR-component GARCH-DCC model to adequately model volatilities and conditional correlations between Bitcoin and fiat currencies. We also perform a rolling window analysis to establish out-of-sample one-step-ahead forecast of dynamic conditional correlations. Such method can help to take into consideration changing variability into the data (Basher and Sadorsky 2016). This leads to compute optimal hedge ratios and thereby cross-hedging (fiat/virtual) currency markets.

The layout of this paper is as follows. Section 2 gives an outline of the methodology adopted. Section 3 presents the data used and the descriptive statistics. Section 4 reports the empirical results. Section 5 highlights cross-hedges for virtual and fiat currency markets. Sections 6 and 7 discusses and concludes, respectively.

\section{Related literature}

Many researchers have largely focused on the role of Bitcoin in well-diversified portfolios. For instance, by employing dynamic conditional correlation model, Bouri et al. (2016b) analyze if Bitcoin can play a role of hedge and safe haven for major world stock indices, bonds, oil, gold, the general commodity index and the US dollar index. They report that Bitcoin is weak hedge but seems to be diversifier. They also indicate that Bitcoin is strong safe haven against Asian stocks. Bouri et al. (2017a, b) examine if Bitcoin could hedge global uncertainty over the period 17/03/2011-07/10/2016. They display that Bitcoin can be hedged against uncertainty by positively reacting to uncertainty at both higher quantiles and shorter frequency movements of Bitcoin returns. Fang et al. (2018) attempt to investigate if the long-run volatilities of global equities, commodities, bonds and Bitcoin are impacted by global economic policy uncertainty. They also study if the global economic policy uncertainty can affect the correlation between Bitcoin and global equities, commodities, and bonds. The empirical results show that the long-run volatilities of global equities, commodities and Bitcoin are affected by global economic policy uncertainty. So, the use of information about the state of global economic 
uncertainty can improve the predictions of Bitcoin volatility. They also report that global economic policy uncertainty negatively (resp. positively) influences the Bitcoin-bonds (resp. both Bitcoin-equities and Bitcoin-commodities) correlation. Such results indicate that Bitcoin can act as a hedge under specific economic uncertainty conditions. Corbet et al. (2018) examine the relationships between cryptocurrencies and some financial assets. They report that cryptocurrency markets can be considered as a new investment asset class given that they are interconnected with each other and have some similar patterns of connectedness with other asset classes. They also display that digital currencies can provide diversification gains for investors with short investment horizons. Chan et al. (2018) analyze the hedging and diversifying properties of Bitcoin against the Euro STOXX, Nikkei, Shanghai A-Share, S\&P500, and the TSX Index using different models. They display that Bitcoin seems to be an effective strong hedge for all these indices only under monthly data frequency. Shahzad et al. (2019) examine whether Bitcoin is safe haven against stock market indices over the period 19/07/2010-22/02/2018. They report that Bitcoin, gold, and the commodity index can be weak safe haven in some cases. Using a quantile-on-quantile regression approach, Selmi et al. (2018) analyze the dependence structure between Bitcoin and crude oil in order to assess Bitcoin's safe haven and hedging proprieties. They display that both Bitcoin and gold can be hedges, safe havens and diversifiers for oil movements. Such proprieties seem to depend on market phases of Bitcoin, gold and crude oil (bear, bull and normal phases). Ji et al. (2018) explore the relationships between Bitcoin and other assets using the directed acyclic graph. They report that the Bitcoin market seems to be quite isolated and no particular asset can affect this cryptocurrency market. Nonetheless, lagged relationships between Bitcoin and some assets are well-documented, in particular during the bear market phase of Bitcoin. Bouri et al. (2018) examine the relationships between Bitcoin and other asset classes (equities, stocks, commodities, currencies and bonds) by studying return and volatility spillovers between different assets. They show that Bitcoin returns are related quite closely to those of most of the other assets, particularly commodities. So, the Bitcoin market is entirely not isolated. The significance and sign of the spillovers show some differences in the two market conditions and the direction of the spillovers. In particular, Bitcoin receives more volatility that it transmits.

Urquhart and Zhang (2019) investigate if Bitcoin can be considered as a hedge or safe haven against world currencies. They evaluate the interactions between Bitcoin and currencies at the hourly frequency given that Bitcoin experiences high volatility. Using ADCC model, they display that Bitcoin can be considered as intraday hedge for the CHF, EUR and GBP, and a diversifier for the AUD, CAD and JPY. Wang et al. (2019) examine spillover impacts between Bitcoin and other assets in China and assess Bitcoin's safe haven and hedging proprieties. They use the VARGARCH-BEKK model to analyze mean and volatility spillover effects and correlation structure between Bitcoin and other assets. They find that Bitcoin can be hedged against bonds, stocks and the Shanghai Interbank Offered Rate (SHIBOR) and seems to be safe haven against adverse price changes produced in the monetary market. Kristjanpoller and Bouri (2019) investigate long-range cross-correlations and asymmetric multifractality between some digital currencies (Bitcoin, Litecoin, 
Ripple, Monero and Dash) and fiat currencies (Swiss Franc, Euro, British Pound, Yen and Australian dollar). By using the MF-ADCCA method, they find that a significant asymmetric feature from the cross-correlation generally seems to be multifractal and persistent. Ripple and Monero (resp. Litecoin and Bitcoin) show lower (resp. the most) multifractal behavior. Ghabri et al. (2020) examine the dependence structure between Bitcoin and some financial assets (MSCI world stock index, gold, crude oil and GEISAC Index). They clearly show that the presence of a potential benefit in diversifying the liquidity risk using Bitcoin instead of classical assets. Kliber et al. (2019) analyze the hedge, diversifier and safe haven proprieties of Bitcoin on different stock markets. To do so, they estimate the dynamic conditional correlation between main stock indices and Bitcoin price (in local currencies) as well as main stock indices and the Bitcoin price (in the US dollar). Bitcoin seems to play different roles depending on stock market. Using different wavelet approaches, Al-Yahyaee et al. (2019) study the interactions between Bitcoin and the Volatility Uncertainty Index (VIX). They clearly display that Bitcoin and VIX change over time and at different frequencies. They also show positive (in-phase) comovements between these two variables whereas negative (out-of-phase) comovements are wellpronounced at low and high frequencies.

Conlon et al. (2020) investigate the safe haven proprieties of cryptocurrencies during the outbreak of coronavirus. They analyze if there is a reduction in downside risk through pairing international equity index investments with portfolio allocations to individual cryptocurrencies (Bitcoin, Ethereum and Tether). They show that Bitcoin and Ethereum do not have safe haven capabilities whereas Tether is safe haven for all the indices during the onset of coronavirus. Bouri et al. (2020c) study the safe haven capabilities of Bitcoin, gold and commodity index against world, developed, emerging, USA, and Chinese stock market indices during the period 20/07/2010-22/02/2018. By using the wavelet coherency method, they display that the whole dependence between commodities/gold/Bitcoin and the stock markets tends to be weak at different time scales. In particular, Bitcoin seems to be the least dependent. Su et al. (2020) investigate the role of Bitcoin in preventing different risks related to geopolitical events. They show that positive and negative effects derived from geopolitical risks toward Bitcoin prices. Bouri et al. (2020a) analyze the dynamic diversification capacity against equities. In this respect, they use DCC models to focus on the nexus between cryptocurrency and stock. They highlight that Bitcoin, Ethereum and Litecoin seem to be hedges, especially against Asian Pacific and Japanese equities, with evidence of a time variability in some cases. By using the cross-quantilogram approach, Bouri et al. (2020b) attempt to explore safe haven and hedging proprieties of some digital currencies against bearish fluctuations in the S\&P500 and 10 equity sectors. They support that Bitcoin, Ripple and Stellar are safe havens for all US equity indices whereas Litecoin and Monero are safe havens for the aggregate US equity index and selected sectors. Rehman (2020) investigates the extreme dependence and risk spillover between Bitcoin and commodities (gold, silver, copper, wheat, platinum and palladium) over the period 04/2013-01/2018. The empirical results report the hedge capability of gold for Bitcoin. Rehman (2020) also highlights spillover from Bitcoin to precious metal market in terms of directional spillover from precious metals to Bitcoin; Silver remains insensitive to any 
downside risk spillover. Rehman et al. (2020) examine the risk dependence between Bitcoin and Islamic equity markets. They report dynamic dependence between many Islamic index and Bitcoin. They also use VaR, CoVaR and $\Delta \mathrm{CoVaR}$ measures to assess spillover between Bitcoin and Islamic equity markets. VaR of Bitcoin seems to surpass from $\mathrm{VaR}$ of Islamic indices and CoVaR of both Islamic and Bitcoin exceeds their respective VaR, indicating the existence of risk spillover between each other.

\section{Empirical models}

In this paper, we use the VAR-DCC-GARCH model, VAR-ADCC-GARCH model and VAR-component GARCH-DCC model. The DCC model of Engle (2002), the ADCC model of Cappiello et al. (2006) and VAR-component GARCH-DCC model of Engle and Lee (1999) are employed to model and estimate in a more suitable manner the volatility dynamics, conditional correlations and hedge ratios between Bitcoin and virtual currency markets.

\subsection{VAR-DCC-GARCH model}

The VAR-DCC-GARCH model allows us to assess the extent of short-run comovements between Bitcoin and fiat currencies. We rely on dynamic conditional correlations obtained from the estimation of the following multivariate DCC-GARCH model of Engle (2002). In this regard, we consider the following process system ${ }^{1}$ :

$$
\left\{\begin{array}{l}
R_{t}=\mu+\Phi R_{t-1}+\varepsilon_{t} \\
\varepsilon_{t}=H_{t}^{1 / 2} \eta_{t}
\end{array}\right.
$$

where $R_{t}$ is a $(l \times l)$ vector of equity returns, $\mu$ is a $(l \times l)$ vector of constant terms, $\Phi=\operatorname{diag}\left(\phi_{1}, \phi_{2}, \ldots, \phi_{l}\right)$ is a $(l \times l)$ diagonal matrix of coefficients, $\varepsilon_{t}$ is a $(l \times l)$ vector of the error terms of the conditional mean equations and $\eta_{t}$ is a sequence of i.i.d. random errors. The conditional variance-covariance matrix $H_{t}$ is defined as follows:

$$
H_{t}=D_{t} P_{t} D_{t}
$$

where $D_{t}=\operatorname{diag}\left(\sqrt{h_{t}^{1}}, \sqrt{h_{t}^{2}}, \ldots \sqrt{h_{t}^{l}}\right)^{2}$ and $P_{t}$ is the $(l \times l)$ conditional correlation matrix varying over time, i.e.,

\footnotetext{
${ }^{1}$ The Bayesian information criteria are used to determine the optimal VAR Order. The results (not reported in this paper) are in favor of the VAR-DCC-GARCH $(1,1)$ process to model the volatility dynamics and conditional correlations between selected assets. These results will be available upon request.

${ }^{2}$ The conditional variances are specified as univariate $\mathrm{GARCH}(1,1)$ processes.
} 


$$
P_{t}=\left(\operatorname{diag}\left(Q_{t}\right)\right)^{-1 / 2} Q_{t}\left(\operatorname{diag}\left(Q_{t}\right)\right)^{-1 / 2}
$$

The conditional volatility $h$ can be written as:

$$
h_{i, t}=\omega_{i}+\alpha_{i} \varepsilon_{i, t-1}^{2}+\beta_{i} h_{i, t-1}
$$

where $Q_{t}=\left(1-\theta_{1}-\theta_{2}\right) \bar{Q}+\theta_{1} \eta_{t-1} \eta_{t-1}^{\prime}+\theta_{2} Q_{t-1}$ is the $(l \times l)$

is a symmetric positive definite matrix, $\bar{Q}$ is the $(l \times l)$ matrix of unconditional variances of the standardized errors $\eta_{t}$. The coefficients $\theta_{1}$ and $\theta_{2}$ are nonnegative scalars as the mean-reverting condition is satisfied, $\theta_{1}+\theta_{2}<1$. The conditional correlation coefficient between two assets, $\rho_{i j, t}$, is then given by:

$$
\rho_{i j, t}=\frac{\left(1-\theta_{1}-\theta_{2}\right) \bar{q}_{i j}+\theta_{1} \eta_{i, t-1} \eta_{j, t-1}+\theta_{2} q_{i j, t-1}}{\left(\left(1-\theta_{1}-\theta_{2}\right) \bar{q}_{i i}+\theta_{1} \eta_{i, t-1}^{2}+\theta_{2} q_{i i, t-1}\right)^{1 / 2}\left(\left(1-\theta_{1}-\theta_{2}\right) \bar{q}_{j j}+\theta_{1} \eta_{j, t-1}^{2}+\theta_{2} q_{j j, t-1}\right)^{1 / 2}}
$$

where $q_{i j, t}$ is the element of the $i$ th row and $j$ th column of the matrix $Q_{t}$. The model is estimated by the maximum likelihood estimation method based on the optimization algorithm of Berndt-Hall-Hall-Hausman (BHHH).

\subsection{VAR-ADCC-GARCH model}

We also choose to employ the ADCC-GARCH model developed by Cappiello et al. (2006). The selection of such model is motivated by the findings of some researchers such as Zhou and Nicholson (2015) and Badshah (2018). These findings indicate that modeling covariance asymmetry between based on the ADCC model indicates that conditional volatility and correlations between returns increase more after negative return shocks than after positive shocks with the same scale. The model is a simple generalization of the DCC-GARCH model of Engle (2002). ${ }^{3}$

The correlation evolution equation in the ADCC-GARCH model is expressed as follows:

$$
Q_{t}=\left(\bar{Q}-A^{\prime} \bar{Q} A-B^{\prime} \bar{Q} B-G^{\prime} \bar{M} G\right)+A^{\prime} \eta_{t-1} \eta_{t-1}^{\prime} A+B^{\prime} Q_{t-1} B+G^{\prime} m_{t-1} m_{t-1} G
$$

where $\bar{Q}=E\left[\eta_{t-1} \eta_{t-1}^{\prime}\right], A, B$ and $G$ are diagonal coefficient matrices of order $k$, $m_{t}=I\left[\eta_{t}<0\right] \circ \eta_{t}(I[\cdot])$ is a $k$-indicator function that takes 1 if the argument is true and 0 otherwise, and $\circ$ is the Hadamard product, and $\bar{M}=E\left[m_{t} m_{t}^{\prime}\right]$. The correlation matrix is given by $P_{t}=\left(\rho_{i j, t}\right)=Q_{t}^{*-1} Q_{t} Q_{t}^{*-1}$, where $Q_{t}^{*}=\left[\sqrt{q_{i i, t}}\right]$, and the correla-

\footnotetext{
${ }^{3}$ It is worth noting that we use the univariate asymmetric GJR-GARCH $(1,1)$ process developed by Glosten et al. (1993). Other univariate GARCH-type models, including asymmetric models, are also considered, and the Bayesian information criterion is used to compare between them. The results (not reported in this paper) are in favor of the GJR-GARCH $(1,1)$ process to model the volatility dynamics of the stock returns. These results will be available upon request.
} 
tion coefficient is $\rho_{i j, t}=q_{i j, t} / \sqrt{q_{i i, t} q_{j j, t}}$. Cappiello et al. (2006) suggest to estimate the model based on the maximum likelihood method. In case of no normality, the results are deemed as the standard QMLE (quasi-maximum likelihood estimation) results.

\subsection{VAR-component GARCH-DCC model}

To decompose the volatility clustering into transitory and permanent shocks, we prefer to use the VAR-DCC based on component GARCH model developed by Engle and Lee (1999). The component GARCH model provides an interesting extension of the classic GARCH model and can expressed as follows:

$$
\begin{gathered}
\Delta r_{t}=\mu_{0}+\sum_{i=1}^{p} \mu_{i} \Delta r_{t-1}+\varepsilon_{t} \\
\sigma_{t}^{2}-q_{t}=\alpha\left(\varepsilon_{t-1}^{2}-q_{t-1}\right)+\beta\left(\sigma_{t-1}^{2}-q_{t-1}\right) \\
q_{t}=\omega+\rho\left(q_{t-1}-\omega\right)+\Phi\left(\varepsilon_{t-1}^{2}-\sigma_{t-1}^{2}\right)
\end{gathered}
$$

where $\Delta r_{t}$ is the first difference operator and $\varepsilon_{t}$ is the time-varying error term (i.e., a measure of conditional volatility $\sigma_{t}^{2}$ ). Equation (8) shows the specific conditional mean equation that follows an autoregressive process, the order (p) of which is selected based on uncorrelated errors. Equations (9) and (10) decompose the transitory and permanent effect of conditional volatility, ${ }^{4}$ respectively.

The correlation evolution equation in the VAR-Component GARCH-DCC model remains the same for the VAR-DCC-GARCH model expressed in Eq. (5).

\section{Data and preliminary analyses}

We consider Bitcoin and three fiat currencies exchange rates expressed as the dollar price of foreign currency, namely EUR, GBP and JPY over the period from February 02,2012 , to November 30, 2017, a total of 1521 observations. The choice of selected fiat currencies and Bitcoin is due to the fact that portfolio holders (e.g., banks, investment fund and portfolio holders) tend to include generally currencies in their portfolios to hedge position and maintain assets liquidity. Also, the behavior of Bitcoin compared to conventional fiat currencies still remains unexplored, especially the presence and features (e.g., asymmetry) of cross-correlation between Bitcoin and conventional fiat currencies. The data are obtained from the website "www. investing.com".

\footnotetext{
${ }^{4}$ Note that the conditional volatility is mean reverting around the permanent volatility $q_{t}$, the latter converges to its mean of $\gamma /(1-\rho)$. Accordingly, $\sigma_{t}^{2}-q_{t}$ measures the transitory component of volatility with the speed of mean reversion of $(\alpha+\beta)$. Given that the permanent volatility is more persistent than the transitory volatility, it is expected that $0<(\alpha+\beta)<\rho<1$.
} 

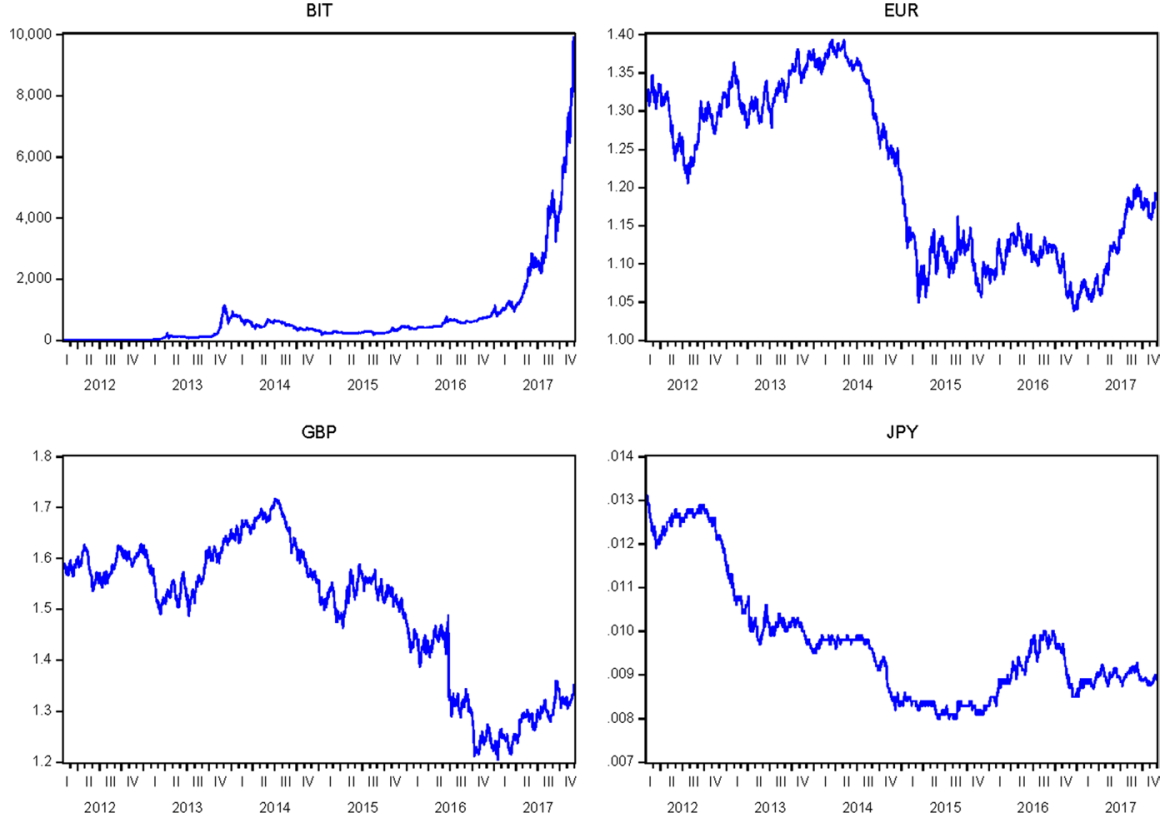

Fig. 1 Dynamic patterns of currencies prices

Figure 1 displays that the time series plots of Bitcoin and fiat currencies over the sample period. The graphical evidence clearly seems to exhibit cyclical movements.

Figure 1 plots the behavior of currencies prices over the period 02/02/2012-30/11/2017. Different behaviors of currencies prices are well-pronounced.

Afterward, the continuously compounded daily returns for Bitcoin and fiat currencies are expressed in percentage computed by multiplying the first difference of the logarithm of currency prices by 100: $R_{t}=\operatorname{Ln}\left(\frac{P_{t}}{P_{t-1}}\right) \times 100$ where $P_{t}$ and $\mathrm{P}_{t-1}$ are the closing prices in market $i$ at time $t$ and $t-1$. Table 1 reports a snapshot of descriptive statistics for daily returns of Bitcoin and fiat currencies. From Table 1, we show that the average return ranges from $-0.010 \%$ for GBP to $0.486 \%$ for Bitcoin. EUR seems to be the least risky as it records the lowest standard deviation (0.529) among all the assets while Bitcoin is the most risky one with the highest standard deviation (5.250). The skewness coefficient is negative (resp. positive) for GBP and Bitcoin (resp. EUR and JPY) returns series, proving that the return distribution has a left tail (resp. right tail). For only Bitcoin and GBP, the kurtosis coefficient is highly significant (resp. exceeding three), showing that the distribution of daily return is leptokurtic. The Jarque-Bera statistics are significant even at very low levels. Hence, the daily returns of Bitcoin and fiat currencies are not normally distributed. Figure 2 plots the daily returns of Bitcoin and fiat currencies. Many interesting facts emerge 
Table 1 Descriptive statistics and statistical properties of return series

\begin{tabular}{lllll}
\hline Series & BIT & EUR & GBP & JPY \\
\hline Observations & 1520 & 1520 & 1520 & 1520 \\
Mean & 0.486 & -0.007 & -0.010 & -0.026 \\
Median & 0.271 & -0.004 & -0.006 & 0.000 \\
Maximum & 38.049 & 3.025 & 2.985 & 3.279 \\
Minimum & -35.059 & -2.417 & -8.402 & -3.774 \\
Std.dev & 5.250 & 0.529 & 0.557 & 0.733 \\
Coef.var & 10.805 & -80.310 & -54.367 & -28.638 \\
Skewness & -0.357 & 0.160 & -2.250 & 0.000 \\
Kurtosis & 10.133 & 2.182 & 35.326 & 1.897 \\
JB & $6535.401 * * *$ & $307.954 * * *$ & $80,317.241 * * *$ & $227.835 * * *$ \\
ARCH LM test(1) & $156.151^{* * *}$ & $29.435 * * *$ & $44.059 * * *$ & $15.905 * * *$ \\
ARCH LM test(5) & $283.903 * * *$ & $57.774 * * *$ & $53.184 * *$ & $23.845^{* * *}$ \\
ARCH LM test(10) & $293.132 * * *$ & $69.326 * * *$ & $58.464 * * *$ & $32.371^{* * *}$ \\
\hline
\end{tabular}

$*$, ** and $* * *$ indicate the rejection of the null hypothesis of the corresponding tests at 1,5 and $10 \%$ levels, respectively
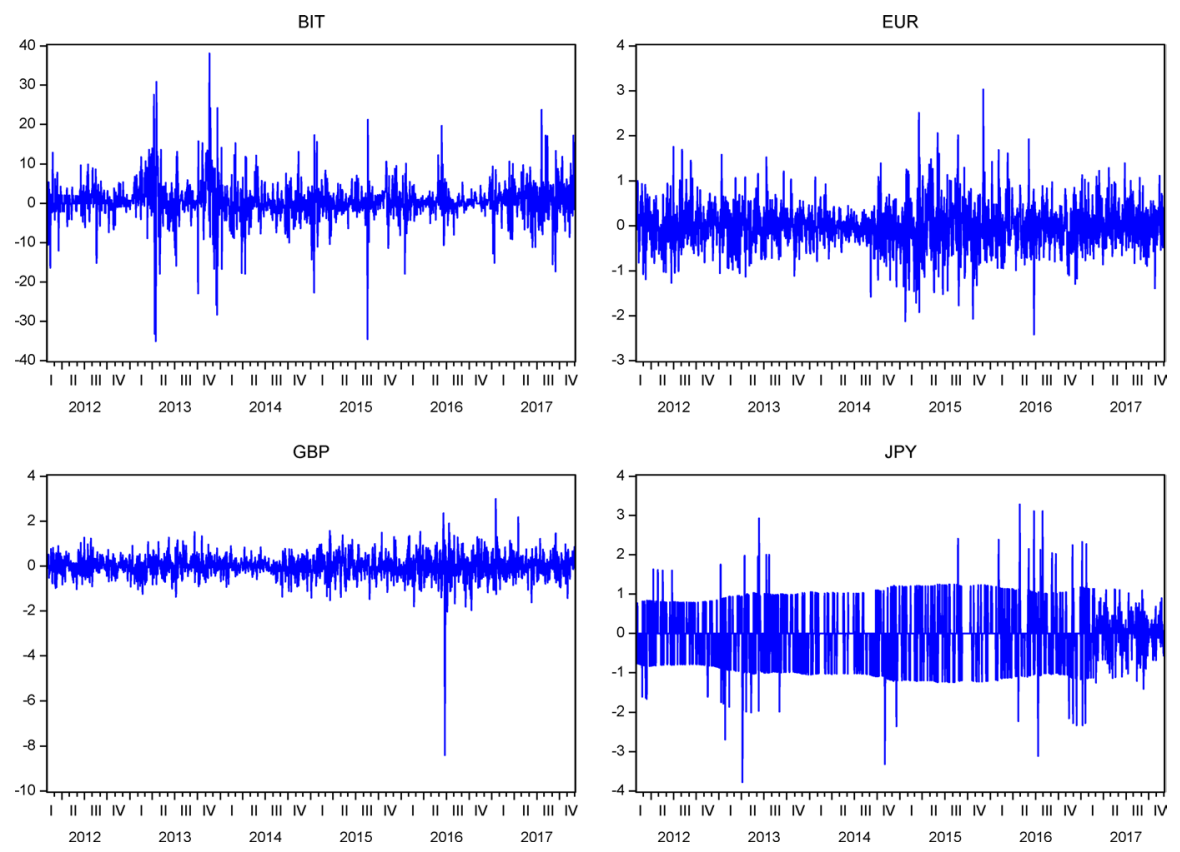

Fig. 2 Dynamic patterns of currencies price returns 
Table 2 Empirical unconditional correlations between Bitcoin and fiat currencies

\begin{tabular}{lllll}
\hline Level series & BIT & EUR & GBP & JPY \\
\hline BIT & 1 & -0.201 & -0.483 & -0.279 \\
EUR & & 1 & 0.763 & 0.585 \\
GBP & & & 1 & 0.370 \\
JPY & & EUR & GBP & 1 \\
\hline Return & BIT & 0.001 & -0.014 & JPY \\
\hline BIT & 1 & 1 & 0.534 & 0.023 \\
EUR & & & 1 & 0.260 \\
GBP & & & & 0.086 \\
JPY & & & & 1 \\
\hline
\end{tabular}

from Fig. 2: (1) all return series tend to fluctuate over time; (2) GBP appears to be less volatile than others; and (3) they seem to have volatility clustering behavior.

Table 1 presents a synopsis of descriptive statistics of the returns of different assets over the period 02/02/2012-30/11/2017.

Figure 2 plots the behavior of currencies prices over the period 02/02/2012-30/11/2017. At first glance, some different patterns in the evolution of currencies prices with different bearish and bullish market phases.

The correlation matrix is reported in Table 2. More precisely, the first part of Table 2 reports the unconditional correlation estimates between Bitcoin and fiat currencies prices whereas the second part presents the unconditional correlation estimates between daily returns of different assets. At first glance, a negative correlation between Bitcoin and fiat currencies is well-documented at price level which still remains negative for only Bitcoin/GBP pair at return level. The average estimated unconditional correlation coefficient between fiat currencies $(0.763$ for EUR/GBP pair, 0.370 for GBP/JPY pair and 0.585 for JPY/GBP pair) is much better than the correlation estimates between Bitcoin and fiat currencies $(-0.201$ for Bitcoin/EUR pair, -0.483 for Bitcoin/GBP pair and -0.279 for Bitcoin/JPY pair) at price level. At return level, rather, the unconditional correlation estimates between different assets seem not to be high enough, expect for the EUR/GBP pair (0.534). This can be a prima facie evidence to study and examine the advantage of combining virtual and fiat currencies.

Table 2 reports the correlations between assets which assess the relationships between fiat currencies and Bitcoin.

\section{Empirical results and interpretation}

Several versions of DCC models reported in Sect. 3 are estimated to improve the specification and give more information about the conditional volatility structure of selected series. First, we report the estimation results from the aforementioned models for Bitcoin and fiat currencies. Second, we produce a rolling window analysis 
Table 3 Estimates of bivariate VAR(1)-DCC-GARCH(1,1) model

\begin{tabular}{|c|c|c|c|c|}
\hline & BIT & EUR & GBP & JPY \\
\hline$\omega$ & $\begin{array}{l}0.8368^{* *} \\
(0.3535)\end{array}$ & $\begin{array}{l}0.0007 \\
(0.0006)\end{array}$ & $\begin{array}{l}0.0023^{*} \\
(0.0012)\end{array}$ & $\begin{array}{l}0.0967 \\
(0.1257)\end{array}$ \\
\hline$\alpha_{1}$ & $\begin{array}{l}0.2208 * * * \\
(0.0269)\end{array}$ & $\begin{array}{l}0.0342 * * * \\
(0.0033)\end{array}$ & $\begin{array}{l}0.0392 * * * \\
(0.0076)\end{array}$ & $\begin{array}{l}0.2519 * * * \\
(0.0838)\end{array}$ \\
\hline$\beta_{1}$ & $\begin{array}{l}0.7782 * * * \\
(0.0357)\end{array}$ & $\begin{array}{l}0.9640 * * * \\
(0.0018)\end{array}$ & $\begin{array}{l}0.9532 * * * \\
(0.0068)\end{array}$ & $\begin{array}{l}0.7471 * * * \\
(0.1722)\end{array}$ \\
\hline skew & $\begin{array}{l}1.0340 * * * \\
(0.0226)\end{array}$ & $\begin{array}{l}0.9917 * * * \\
(0.0329)\end{array}$ & $\begin{array}{l}0.9801 * * * \\
(0.0305)\end{array}$ & $\begin{array}{l}0.9792 * * * \\
(0.0071)\end{array}$ \\
\hline shape & $\begin{array}{l}3.1116^{* * * *} \\
(0.1518)\end{array}$ & $\begin{array}{l}6.9515^{* * * *} \\
(1.1611)\end{array}$ & $\begin{array}{l}5.5701 \text { *** } \\
(0.8815)\end{array}$ & $\begin{array}{l}2.5706^{* * *} \\
(0.2037)\end{array}$ \\
\hline$\theta_{1}$ & $\begin{array}{l}0.0232 * * * \\
(0.0054)\end{array}$ & & & \\
\hline$\theta_{2}$ & $\begin{array}{l}0.9384 * * * \\
(0.0187)\end{array}$ & & & \\
\hline mshape & $\begin{array}{l}5.2668^{* * * *} \\
(0.3144)\end{array}$ & & & \\
\hline \multicolumn{5}{|l|}{ Model diagnostics } \\
\hline Akaike & 10.141 & & & \\
\hline Bayes & 10.312 & & & \\
\hline Shibata & 10.139 & & & \\
\hline Hannan-Quinn & 10.205 & & & \\
\hline Obs. & 1520 & & & \\
\hline
\end{tabular}

$*, * *$ and $* * *$ indicate the rejection of the null hypothesis of the corresponding tests at 1,5 and $10 \%$ levels, respectively

fixed at 1021 observations and 500 one-step-ahead dynamic conditional correlations with different models in order to compute optimal hedge ratio in effective way. This section is divided into main subsections.

\subsection{Results from the model estimation}

Tables 3, 4 and 5 report the estimation results of the VAR-DCC with different GARCH setting models under Student-t distributed innovation between Bitcoin and fiat currencies. The power term (skew) of returns for the predictable structure in the volatility pattern is positive and significant for all series.

From Table 3, the estimation results of VAR-DCC-GARCH model show that short-term volatility persistence for all return series is well-documented given that term $\alpha$ is significant at $1 \%$ level. The estimated coefficient $\beta$ is significant at $1 \%$ level for all series, indicating long-term volatility persistence. Bitcoin shows the less magnitude of summation for the GARCH terms. Such results clearly display that Bitcoin exhibits the less speed of convergence of the conditional volatility to its long-run equilibrium. Table 4 reports the estimation results for VAR-ADCC-GARCH model. 
Table 4 Estimates of bivariate VAR(1)-ADCC-GARCH(1,1) model

\begin{tabular}{|c|c|c|c|c|}
\hline & BIT & EUR & GBP & JPY \\
\hline \multirow[t]{2}{*}{$\omega$} & $0.7750 * *$ & 0.0004 & $0.0022 * *$ & 0.1354 \\
\hline & $(0.3383)$ & $(0.0005)$ & $(0.0011)$ & $(0.5582)$ \\
\hline \multirow[t]{2}{*}{$\alpha_{1}$} & $0.2538 * * *$ & $0.0139 * *$ & $0.0218 * *$ & 0.3979 \\
\hline & $(0.0327)$ & $(0.0057)$ & $(0.0099)$ & $(0.4576)$ \\
\hline \multirow[t]{2}{*}{$\beta_{1}$} & $0.7863^{* * *}$ & $0.9723 * * *$ & $0.9548 * * *$ & 0.7032 \\
\hline & $((0.0366)$ & $(0.0037)$ & $(0.0053)$ & $(0.6980)$ \\
\hline \multirow[t]{2}{*}{$\gamma_{1}$} & $-0.0809 *$ & $0.0255^{* * *}$ & $0.0321 *$ & -0.2071 \\
\hline & $0.0416)$ & $(0.0083)$ & $(0.0173)$ & $(0.5902)$ \\
\hline \multirow[t]{2}{*}{ skew } & $1.0312 * * *$ & $0.9975 * * *$ & $0.9799 * * *$ & $0.9822 * * *$ \\
\hline & $(0.0227)$ & $(0.0335)$ & $(0.0306)$ & $(0.0113)$ \\
\hline \multirow[t]{2}{*}{ shape } & $3.1269 * * *$ & $7.4759 * * *$ & $5.6677 * * *$ & $2.4953 * * *$ \\
\hline & $(0.1544)$ & $(1.2967)$ & $(0.9470)$ & $(0.1549)$ \\
\hline \multirow[t]{2}{*}{$\theta_{1}$} & $0.0226^{* * *}$ & & & \\
\hline & $(0.0050)$ & & & \\
\hline \multirow[t]{2}{*}{$\theta_{2}$} & $0.9399 * * *$ & & & \\
\hline & $(0.0175)$ & & & \\
\hline \multirow[t]{2}{*}{$\theta_{3}$} & 0.0000 & & & \\
\hline & $(0.0057)$ & & & \\
\hline \multirow[t]{2}{*}{ mshape } & $5.2253 * * *$ & & & \\
\hline & $(0.3097)$ & & & \\
\hline \multicolumn{5}{|l|}{ Model diagnostics } \\
\hline Akaike & 10.168 & & & \\
\hline Bayes & 10.357 & & & \\
\hline Shibata & 10.165 & & & \\
\hline Hannan-Quinn & 10.238 & & & \\
\hline Obs. & 1520 & & & \\
\hline
\end{tabular}

$*, * *$ and $* * *$ indicate the rejection of the null hypothesis of the corresponding tests at 1,5 and $10 \%$ levels, respectively

The asymmetry coefficient $g$ is positive and significant at $1 \%$ level for EUR return series, suggesting that the EUR exhibits asymmetric conditional volatility. Accordingly, negative shocks increase the volatility of EUR exchange rate market more than positive shocks. GBP clearly shows significant asymmetric effect over the period $02 / 02 / 2012-30 / 11 / 2017$. The asymmetry coefficient $g$ is significantly negative for Bitcoin series, implying that Bitcoin exhibits asymmetric conditional volatility.

Table 5 reports estimation results for VAR(1)-Component GARCH(1,1)-DCC model. From Table 5, we display that Bitcoin and fiat currencies show different risk behaviors in terms of transitory and permanent effects. Bitcoin shows the highest value of the transitory volatility (0.8677) and is significant at $1 \%$ level, while fiat currencies show the less value, except for the EUR which is not significant. Such results display more long-term volatility persistence in Bitcoin series. Likewise, Bitcoin shows the highest GARCH value $(0.1426)$ of the permanent 
Table 5 Estimates of bivariate $\operatorname{VAR}(1)$-component GARCH(1,1)-DCC model

\begin{tabular}{|c|c|c|c|c|}
\hline & BIT & EUR & GBP & JPY \\
\hline \multirow[t]{2}{*}{$\omega$} & $0.4503 *$ & $0.0007 * *$ & $0.0021 * * *$ & $0.0213 * * *$ \\
\hline & $(0.2636$ & $(0.0003)$ & $(0.0005)$ & $(0.0043)$ \\
\hline \multirow[t]{2}{*}{$\alpha_{1}$} & $0.0750 * * *$ & 0.0180 & $0.0555^{*}$ & $0.1559 * *$ \\
\hline & $(0.0289)$ & $(0.0296)$ & $(0.0318)$ & $(0.0717)$ \\
\hline \multirow[t]{2}{*}{$\beta_{1}$} & $0.8677 * * *$ & 0.0331 & $0.0476 * * *$ & $0.7248 * * *$ \\
\hline & $(0.0162)$ & $(0.4314)$ & $(0.3373)$ & $(0.1359)$ \\
\hline \multirow[t]{2}{*}{$\rho$} & $0.9959 * * *$ & $0.9983 * * *$ & $0.9923 * * *$ & $0.9947 * * *$ \\
\hline & $(0.0012)$ & $(0.0006)$ & $(0.0005)$ & $(0.0000)$ \\
\hline \multirow[t]{2}{*}{$\phi$} & $0.1426 * * *$ & $0.0331 * * *$ & $0.0314 * * *$ & $0.0608 * * *$ \\
\hline & $(0.0504)$ & $(0.0061)$ & $(0.0102)$ & $(0.0196)$ \\
\hline \multirow[t]{2}{*}{ skew } & $1.0388 * * *$ & $0.9920 * * *$ & $0.9818 * * *$ & $0.9802 * * *$ \\
\hline & $(0.0229)$ & $(0.0335)$ & $(0.0306)$ & $(0.0071)$ \\
\hline \multirow[t]{2}{*}{ shape } & $3.1692 * * *$ & $6.8338 * * *$ & $5.6772 * * *$ & $2.6872 * * *$ \\
\hline & $(0.1725)$ & (1.0915) & $(0.8036)$ & $(0.2195)$ \\
\hline \multirow[t]{2}{*}{$\theta_{1}$} & $0.0229 * * *$ & & & \\
\hline & $(0.0056)$ & & & \\
\hline \multirow[t]{2}{*}{$\theta_{2}$} & $0.9378 * * *$ & & & \\
\hline & $(0.0204)$ & & & \\
\hline \multirow[t]{2}{*}{ mshape } & $5.4892 * * *$ & & & \\
\hline & $(0.3208)$ & & & \\
\hline \multicolumn{5}{|c|}{ Model diagnostics } \\
\hline Akaike & 10.109 & & & \\
\hline Bayes & 10.309 & & & \\
\hline Shibata & 10.107 & & & \\
\hline Hannan-Quinn & 10.184 & & & \\
\hline Obs. & 1520 & & & \\
\hline
\end{tabular}

$*$, ** and $* * *$ indicate the rejection of the null hypothesis of the corresponding tests at 1,5 and $10 \%$ levels, respectively

volatility. Such findings can shed some light on the issue of volatility or shock spillover between Bitcoin and fiat currencies market. As well, Bitcoin has very high value of the autoregressive term (i.e., GARCH term) and the estimated coefficient of shocks (i.e., ARCH term) in the permanent volatility displays high volatility persistence. Fiat currencies show low magnitude and low volatility persistence. Such results can be explained by the dramatic rise in Bitcoin return series.

Table 3 displays the estimation results of VAR-DCC-GARCH model. Most notably, short-term volatility persistence for all return series is well-pronounced.

Table 4 reports the estimation results for VAR-ADCC-GARCH model.

Table 5 presents the estimation results for $\operatorname{VAR}(1)$-Component $\operatorname{GARCH}(1,1)$ DCC model. All in all, Bitcoin and fiat currencies display different risk behaviors in terms of transitory and permanent effects. 
Fig. 3 Time-varying correlations between Bitcoin and fiat currencies returns
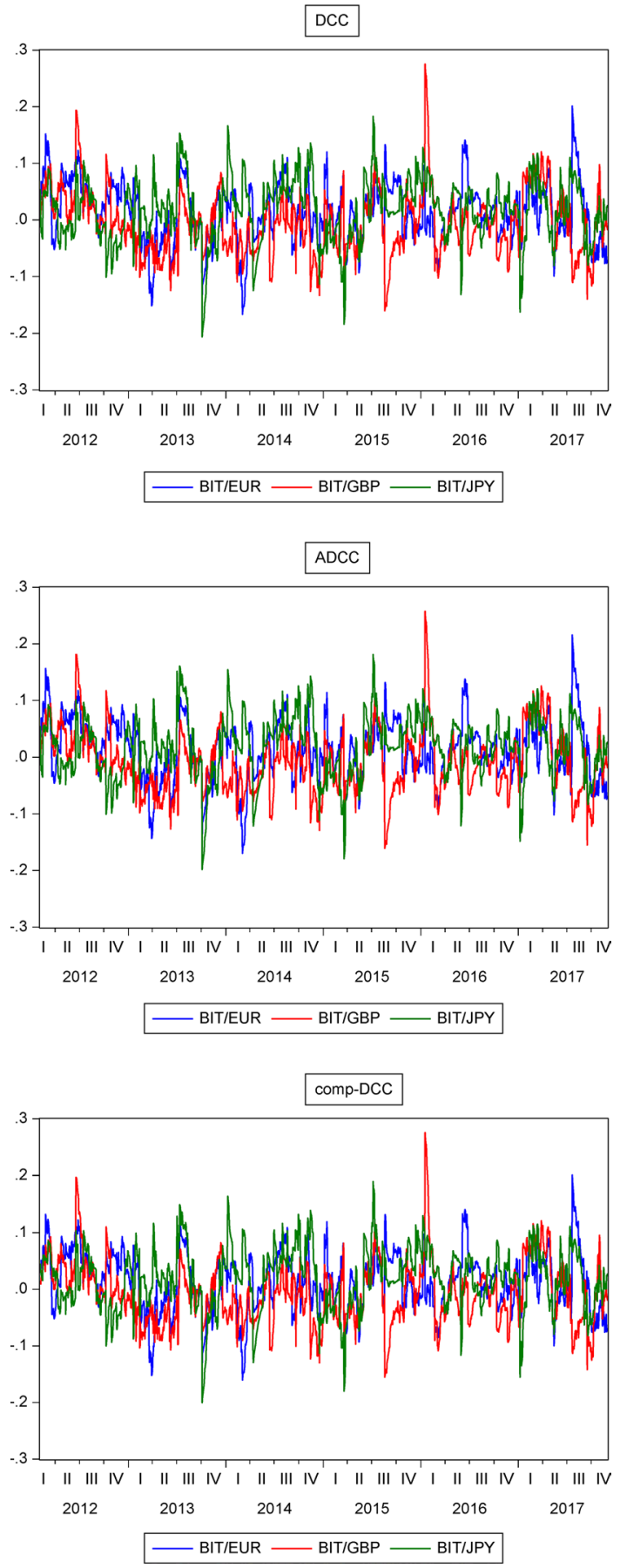
Figure 3 plots the evolution of the fitted time-varying conditional correlation coefficients between Bitcoin and fiat currencies estimated from the VARDCC-GARCH model. All the graphs show that the conditional correlation tends to be instable and ranges between positive and negative values during the period 02/02/2012-30/11/2017. This can be a prima facie evidence of the presence of high and low volatility regimes governing the correlation between Bitcoin and fiat currency markets. Again, such finding suggests the importance of analyzing the benefits and Bitcoin/fiat currencies portfolio diversification.

Figure 3 illustrates the dynamics of the fitted time-varying conditional correlation coefficients between Bitcoin and fiat currencies estimated from the VAR-DCCGARCH model.

\subsection{Dynamic conditional correlations based on a rolling window analysis}

One-step-ahead dynamic conditional correlations are estimated by employing a rolling window analysis. Again, the estimation window is fixed at 1021 observations and 500 one-step-ahead dynamic conditional correlations.

Figure $4 \mathrm{a}, \mathrm{b}$ and $\mathrm{c}$ displays the one-step-ahead dynamic conditional correlations between Bitcoin and fiat currencies for different models. For each Bitcoin/fiat currency pair, the one-step-ahead dynamic conditional correlations retrieved from DCC-GARCH and ADCC-GARCH models seem to be quite similar (Fig. 4a and b, respectively). Such time-varying correlations are rather characterized trending downward over the period under study. The dynamic behavior of correlations for each Bitcoin/fiat currency pair calculated from the component GARCH-DCC model shows a slightly different pattern. They fluctuate between negative and positive values with different magnitudes. Once again, the trending downward seems to dominate the behavior of the time-varying correlation. All the correlations thereby reveal the diversification benefits.

Figure $4 \mathrm{a}, \mathrm{b}$ and $\mathrm{c}$ plots the dynamics of one-step-ahead conditional correlations between Bitcoin and fiat currencies for different models. All in all, different behaviors of conditional correlations are well-documented.

From Table 6, the dynamic conditional correlations computed from the compDCC model seem to be less correlated with those provided from other models for each pair of correlations. The correlations between comp-DCC and DCC models (or ADCC and comp-DCC models) appear to be low compared to others for each pair of correlations. Such findings seem to be consistent with Fig. 4.

Table 6 reports asymmetric behaviors of conditional correlations from different models.

In order to check the robustness of the results, we investigate the news impact correlation surfaces plotted in Fig. 5. The DCC news impact correlation surface between Bitcoin and fiat currencies shows an interesting shape (Fig. 5a). Along the $z_{-} 1$ axis (Bitcoin), the correlation surfaces between Bitcoin and different fiat currencies trace out a positive to a negative pattern. Similarly, along the $z \_2$ axis (fiat currencies), the correlation surfaces trace out a negative to positive relationship. Accordingly, shocks between Bitcoin and fiat currencies show asymmetric 
Fig. 4 a Rolling one-step-ahead DCC conditional correlations, b rolling one-step-ahead ADCC conditional correlations and $\mathbf{c}$ rolling one-step-ahead compDCC conditional correlations
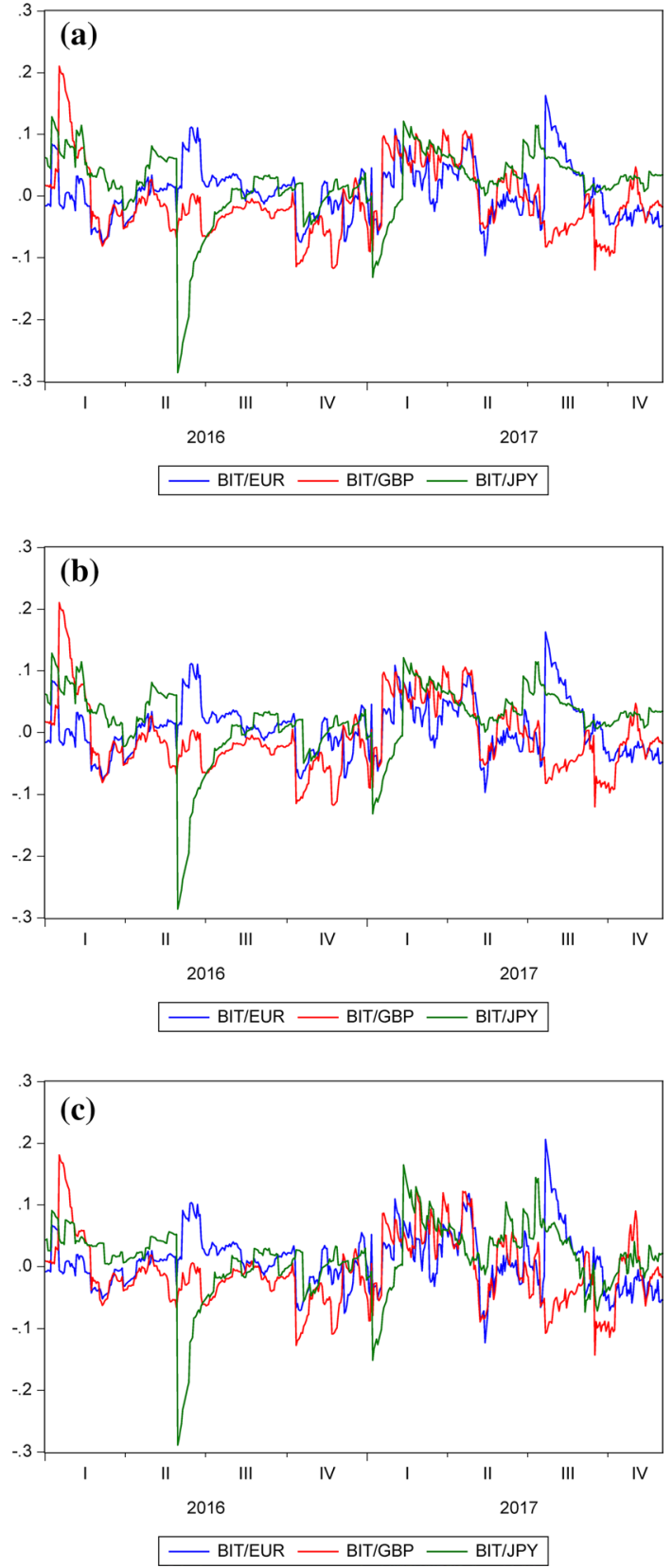

correlation effects. Moreover, the ADCC-GARCH and Component GARCH-DCC news impact correlation surfaces between Bitcoin and fiat currencies display a very similar shape to that obtained from the DCC model (Fig. 5b and c). 
Table 6 Correlations between correlations

\begin{tabular}{llll}
\hline & BIT/EUR & BIT/GBP & BIT/JPY \\
\hline DCC/ADCC & 0.9910 & 0.9964 & 0.9963 \\
DCC/comp-DCC & 0.9684 & 0.9703 & 0.9478 \\
ADCC/comp-DCC & 0.9764 & 0.9707 & 0.9469 \\
\hline
\end{tabular}

(a) DCC News Impact Correlation Surface

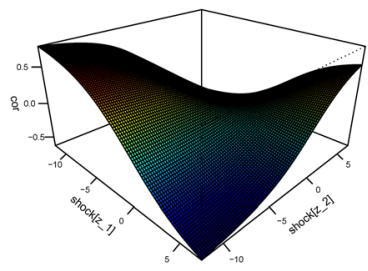

DCC Nows Impact Correlation Surface

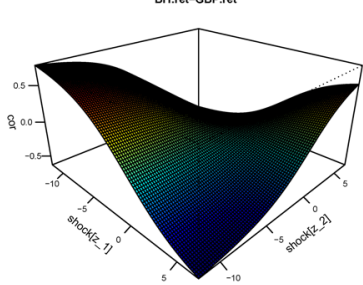

DCC News Impact Correlation Surface

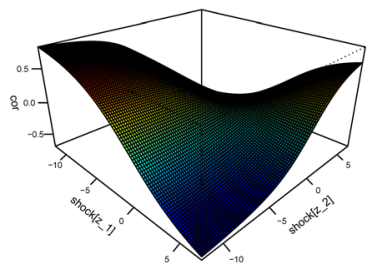

(b)

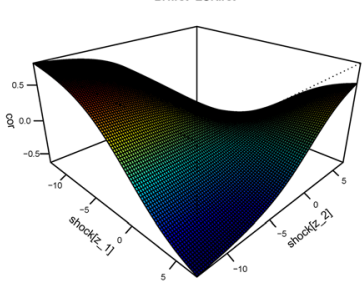

DCC News Impact Correlation Surface

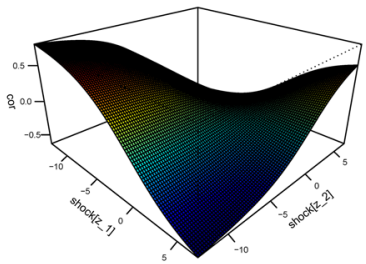

DCC Nows Impact Correlation Surface

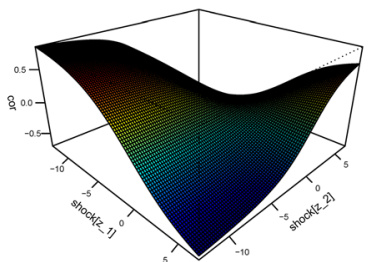

(C) DCC News Impact Correlation Surface

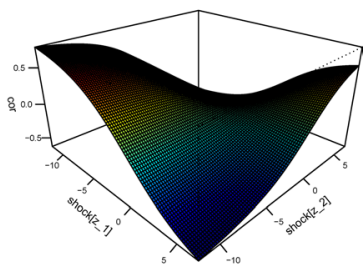

DCC News Impact Correlation Surface

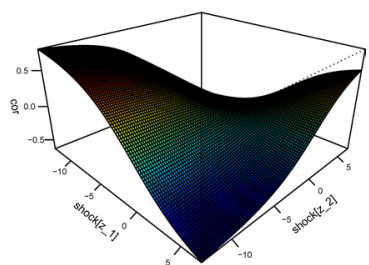

DCC News Impact Correlation Surface

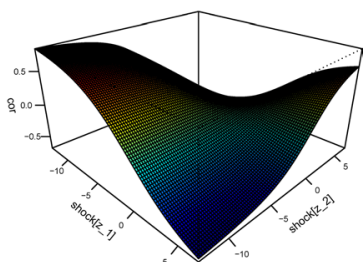

Fig. 5 a DCC news impact correlation surface, b ADCC news impact correlation surface and c compDCC news impact correlation surface

Figures 5 illustrate the behaviors of the news impact correlation surfaces estimated from different models.

\section{Hedging Bitcoin with fiat currencies: evidence from optimal hedging ratios}

This section successively presents how to compute the optimal hedge ratio and thus the dynamic hedging strategies. Afterward, the empirical results are reported in details. 


\subsection{Hedging design}

The empirical findings from analyzing and modeling the volatility dynamics of Bitcoin and fiat currencies as well as the dynamic correlation between different currencies lead us to raise the question if it is possible to establish hedging strategies. Most notably, as point out by Daniel (2001), hedging strategies can significantly diminish price volatility and also bring in higher predictability and certainty without decreasing returns. To this end, we consider a hedged portfolio made up of Bitcoin and each selected fiat currency in which an investor seeks to protect himself from exposure to Bitcoin price movements by investing in fiat currency. From empirical standpoint, the estimated conditional covariance from the aforementioned models can be employed to compute optimal hedge ratios. Given a portfolio of Bitcoin and fiat currency, and following Basher and Sadorsky (2016), the optimal hedge ratio is the one that minimizes the risk of the portfolio, as be explained as follows.

Let $R_{H P, t}$ the return of a portfolio composed by the Bitcoin and fiat currency. It can be written as:

$$
R_{H P, t}=R_{B, t}-\lambda_{t} R_{f, t}
$$

where $R_{H P, t}$ is the return on the hedged portfolio, $R_{B, t}$ is the return of Bitcoin and $R_{f, t}$ is the return of fiat currency and $\lambda_{t}$ is the hedge ratio. If the investor is long in the Bitcoin's position (long position), the hedge ratio is the number of fiat currency's unities that has to be sold. In other words, a long position in one asset can be hedged with a short position in a second asset. Afterward, and following Basher and Sadorsky (2016), the variance of the hedged portfolio conditional on the information set at time $t-1$ can be expressed as follows:

$$
\operatorname{var}\left(R_{H P, t} \mid I_{t-1}\right)=\operatorname{var}\left(R_{B, t} \mid I_{t-1}\right)-2 \lambda_{t} \operatorname{cov} \operatorname{ar}\left(R_{f, t}, R_{B, t} \mid I_{t-1}\right)+\lambda_{t}^{2} \operatorname{var}\left(R_{f, t} \mid I_{t-1}\right)
$$

The optimal hedge ratios represent the $\lambda_{t}$ that minimizes the conditional variance of the hedged portfolio. The optimal hedge ratio conditional on the information set $I_{t-1}$ can be provided by taking the partial derivative of the variance with respect to $\lambda_{t}$ and setting the formula equal to zero (see, Baillie and Myers 1991):

$$
\lambda_{t}^{*} \mid I_{t-1}=\frac{\operatorname{cov}\left(R_{B, t}, R_{f, t} \mid I_{t-1}\right)}{\operatorname{var}\left(R_{f, t} \mid I_{t-1}\right)}
$$

As previously indicated, we obtain the conditional volatility from three types of models to build hedge ratio, as recommended by Kroner and Sultan (1993). Therefore, the hedge ratio between Bitcoin and fiat currency can be expressed as follows:

$$
\lambda_{t}^{*}=h_{B f, t} / h_{f, t}
$$

where $h_{B f, t}$ represents the conditional covariance between Bitcoin and fiat currency and $h_{f, t}$ is considered as the conditional variance of fiat currency returns. Once 
Fig. 6 Rolling one-step-ahead optimal hedge ratios for different models. a Rolling onestep-ahead DCC optimal hedge ratios, b rolling one-step-ahead ADCC optimal hedge ratios and c rolling one-step-ahead component GARCH-DCC optimal hedge ratios
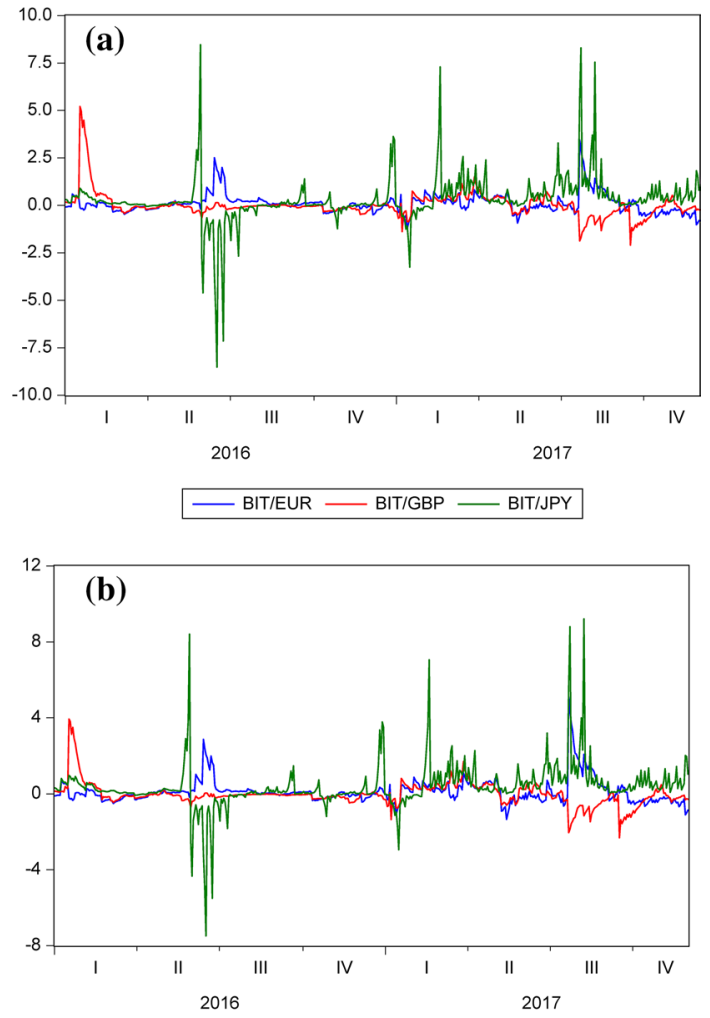

BIT/EUR — BIT/GBP $-\mathrm{BIT/JPY}$

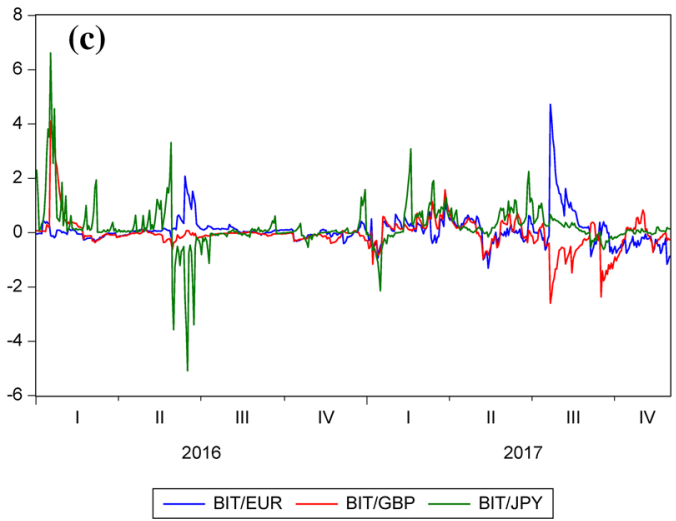

computed, the optimal hedge ratio allows us to build a dynamic hedging strategy which consists on long position of 1 Bitcoin and a short position of $\lambda$ amount in fiat currency.

Afterward, we found the out-of-sample hedge ratios based on a rolling window analysis. In this respect, we make a one-period-ahead conditional volatility forecast 
Table 7 Correlations between hedges ratios

\begin{tabular}{llll}
\hline & BIT/EUR & BIT/GBP & BIT/JPY \\
\hline DCC/ADCC & 0.9789 & 0.9846 & 0.9929 \\
DCC/comp-DCC & 0.9628 & 0.9656 & 0.6639 \\
ADCC/comp-DCC & 0.9814 & 0.9805 & 0.6328 \\
\hline
\end{tabular}

at time period $t$ and these forecasts can be employed to establish a one-period-ahead hedge ratio. Then, we use the forecasted hedge ratios to construct the hedged portfolio. A rolling window size of 1021 observations is employed to establish 500 oneperiod-ahead hedge ratios.

\subsection{Empirical results of hedging}

Figure $6 \mathrm{a}, \mathrm{b}$ and $\mathrm{c}$ displays the time-varying optimal hedge ratios estimated between Bitcoin and fiat currency (EUR, GBP and JPY) under DCC, ADCC and component GARCH-DCC models, respectively.

Figure $6 \mathrm{a}, \mathrm{b}$ and $\mathrm{c}$ plots the dynamic optimal hedge ratios estimated between Bitcoin and fiat currency.

At first glance, each optimal hedge ratio plotted in Fig. 6 does not evolve in the same way according to the selected model and fiat currency, even though all plots clearly exhibit cyclical swings. The hedge ratio for all portfolios (Bitcoin and fiat currency) tends to be low or even negative in some periods while it increases during other periods, implying varying costs for hedging risk. This is obviously due to the dynamics of correlation between assets (as clearly shown in Figs. 3 and 4). Figure 6 also shows the existence of frequent and large spikes during the period, implying thus demand frequent rebalancing. From Fig. 6, different plots clearly show that the optimal hedge ratios computed between Bitcoin and Yen (BIT/JPY) perform very well over time, implying a greater hedging effectiveness. However, the DCC optimal hedge ratios calculated between Bitcoin and GBP (BIT/GBP) provide a low hedging effectiveness given the low values recorded by hedge ratio over time. Note also that the component GARCH-DCC optimal hedge ratios display more variability than either DCC or ADCC models, especially for BIT/JPY pair. Such results can be explained by the ability of component GARCH-DCC model to take into account some stylized facts in time series by decomposing volatility into transitory and permanent shocks. Overall, as reported by Cabera and Schulz (2016), the time-varying behavior of hedge ratio clearly indicates that for a sustainable risk management a dynamic hedging strategy is prominent.

Looking afterward deeper into correlations between the hedge ratios calculated from different models, we report the empirical results in Table 7.

Table 7 reports the correlations between the hedge ratios calculated from different models.

From Table 7, the correlations between the hedge ratios under different models are high (above 0.9), except for BIT/JPY pairs (0.6639) from DCC/component GARCH-DCC models and 0.6328 from ADCC/component GARCH-DCC models. 
Table 8 Hedge ratio summary statistics

\begin{tabular}{lrll}
\hline & \multicolumn{1}{c}{ Mean } & Min & Max \\
\hline BIT/EUR & & & \\
DCC & 0.089 & -1.246 & 3.438 \\
ADCC & 0.005 & -2.085 & 5.209 \\
comp-DCC & 0.311 & -8.517 & 8.463 \\
BIT/GBP & & & \\
DCC & 0.113 & -1.344 & 5.094 \\
ADCC & -0.034 & -2.317 & 3.927 \\
comp-DCC & 0.373 & -7.491 & 9.208 \\
BIT/JPY & & & \\
DCC & 0.089 & -1.3 & 4.715 \\
ADCC & -0.042 & -2.599 & 4.096 \\
comp-DCC & 0.222 & -5.086 & 6.61 \\
\hline
\end{tabular}

This again confirms the aforementioned findings. The component GARCH-DCC model tends to more highlight the returns properties of time series, implying a difference in estimating the hedge ratios.

Table 8 summarizes a snapshot of the descriptive statistics for hedge ratio, including the mean, minimum and maximum. As indicated by Cabera and Schulz (2016), the lower the hedge ratio, the cheaper it is to hedge.

Table 8 reports a set of the descriptive statistics for hedge ratio (mean, minimum and maximum).

The average value of the hedge ratio between BIT and EUR is 0.089 under the VAR-DCC-GARCH model, implying that one Bitcoin (long position) can be hedged for 8.9 cents of EUR (short position). On the contrary, for the VAR-ADCC-GARCH model, the average value of the hedge ratio between BIT and EUR equals to 0.005, indicating that one Bitcoin tends to shorted by 0.5 cents of EUR. The highest hedge ratio is 0.311 under the VAR-Component GARCH-DCC model. This finding indicates that investor requires more amount of EUR when investing in the Bitcoin market by using the component GARCH-DCC compared to other models.

Table 8 also displays that the average value of the hedge ratio for BIT/GBP pair is 0.113 for the VAR-DCC-GARCH model and -0.034 for the VAR-ADCC-GARCH model and -0.373 for the VAR-Component GARCH-DCC model. Notice that an average hedge ratio equals to -0.034 indicates that one Bitcoin is hedged by 34 cents of GBP (long position). Again, the VAR-Component GARCH-DCC model shows the highest hedge ratio.

For the BIT/JPY pair, the average value of hedge ratio is equal to 0.089 under the VAR-DCC-GARCH model, -0.042 under the VAR-Component GARCH-DCC model. The VAR-Component GARCH-DCC model again displays that the highest value of hedge ratio is 0.222 .

Given the aforementioned results, some interesting findings can be revealed. Unlike, VAR-Component GARCH-DCC model requires more amount of fiat currency to minimize the risk when investing in the Bitcoin market. In spite of the high 
price volatility of Bitcoin, the average hedge ratio seems to be very low, regardless of which model is used. This finding can be explained by the hedging ability of Bitcoin against other assets, as increasingly revealed by many researchers such as Bouri et al. (2016a), Dyhrberg (2016a, b).

\section{Discussion}

The fast development of digital currencies has increasingly attracted the attention of regulators, investors and researchers. In particular, investors are searching for alternative investment assets to diversify their portfolios. Despite their volatility, digital currencies are considered as interesting assets given their high average return and low correlation with other assets. That is why the current research shows a keen interest in hedging different assets with cryptocurrencies and in particular how Bitcoin can help in portfolio diversification. Many researchers focus exclusively on the safe haven, diversifier and hedge proprieties of Bitcoin. Nevertheless, it fails to offer a balanced perspective on how cryptocurrencies can be hedged by other assets given Bitcoin presents high volatility. That is why, in this paper, we investigate the ability of fiat currencies to hedge Bitcoin. To do so, we compute optimal hedge ratios between Bitcoin and fiat currencies by employing conditional volatility and correlations estimates of different models over the period under study.

Our empirical results clearly show the joint dynamics of Bitcoin and fiat currencies under different specifications. This led to improve the quality of estimates of optimal hedge ratios between Bitcoin/fiat currency pair. As a matter of fact, the dynamic behavior of hedge ratio based on taking into account dynamic nature of volatilities and correlations between different assets result in an ongoing regular demand to rebalance the hedged positions. On the other hand, using different models which provide information about different aspects of behavior of volatility and correlation leads to better dynamic hedging strategies. Such findings can be of interest to the investors in the virtual market to diversify portfolios by using classical assts. Our paper also contributes to a burgeoning literature on cryptocurrencies and provides more solutions for potential investors which consider virtual currencies as an alternative investment opportunity among many other possible investments (such as stocks, bonds).

\section{Conclusion}

In this paper, we attempt to analyze and model the volatility dynamics of Bitcoin and fiat currencies (EUR, GBP and JPY) over the period 02/02/2012-30/11/2017. Thereafter, based on the dynamic correlations between different currencies, we propose to establish dynamic hedging strategy which can be used by investors to hedge against risk when investing in the Bitcoin market. In this regard, searching for hedging appears to be appropriate given that the high price volatility of Bitcoin is well-documented and it is held for investment purposes rather than being used for transactions, as suggested by many researchers (e.g., Baur et al. 2015). By leafing 
through the hedging and risk management literature, one of the most sweepingly used strategies consists in determining the hedge ratio based on the information available at time t (e.g., Wang and Wu 2012; Arouri et al. 2011; Kroner and Sultan 1993). Obviously, the optimal hedge ratio is represented by the conditional covariance between two assets divided by the conditional variance of second asset returns. Therefore, different conditional covariance and variance understandably produce various optimal hedge ratios. For this end, GARCH-type models are the best fitted models to estimate optimal hedge. In this study, we apply three worthwhile GARCH models, namely the VAR-DCC-GARCH model, VAR-ADCC-GARCH model and VAR-component GARCH-DCC model. The empirical results interestingly show different features of Bitcoin and fiat currencies under different models.

After using the aforementioned models to study the volatility dynamics, we attempt to compute the optimal hedge ratio. Taking into account the time-varying nature in volatility and correlation structure allows us to analyze the behavior of the optimal hedge ratio by using the three models. The empirical results clearly show a time-varying hedge ratio for all Bitcoin/fiat currency pairs which is marked by the large spikes over time, under the three models. This implies varying costs for hedging risk and a demand for frequent rebalancing. On average, the component GARCH-DCC model (resp. ADCC model) involves more (resp. less) amount of fiat currency to minimize the risk when investing in the Bitcoin market which hinders investors to invest a great amount in other asset. Overall, in spite of the high price volatility, the average optimal hedge ratio appears to be very low irrespectively of which model is employed. Further studies can analyze the possibility of hedging Bitcoin with various assets.

By and large, a fledgling economics and finance literature emerge to investigate cryptocurrency structure and behavior and make more solutions for cryptocurrencies investors and portfolio holders. In this respect, our study shows that cryptocurrencies such as Bitcoin can provide a new puzzle for portfolio hedging based on negative dynamic correlations with fiat currencies and safe haven properties. Of course, virtual currencies can be promising among each other for the attention of investors compared to other fiat currencies competitiveness and hedging solutions. As policy implications, exchange risk for international trade exchanges can be safer with cryptocurrencies based on safe haven properties and international diversification based on negative correlations with fiat currencies. Our paper also contributes to a burgeoning literature on cryptocurrencies and provides more solutions for potential investors which consider virtual currencies as an alternative investment opportunity among many other possible investments (such as stocks, bonds). Cryptocurrencies market can be regarded as a special kind of unconventional policy. Similarly, our results are beneficial for banks and central banks monetary and exchange policies. Our new framework provides a new policy intervention for policy makers and central banks decisions based on the safe haven characteristic of cryptocurrencies. If fiat currencies bind in equilibrium, a policy-induced redistribution of cryptocurrencies can improve matter portfolio diversification gains in terms of risk reducing.

Our paper can add to the existing literature that generally investigates the relationships between Bitcoin and other assets by investigating the possibility if Bitcoin can be hedged by selected fiat currencies. This can enrich the literature by creating a 
new avenue of research to analyze the diversification perspectives of cryptocurrency portfolio.

\section{Compliance with ethical standards}

Conflict of interest We declare no conflict interest between all authors in this paper.

Ethical approval This article does not contain any studies with human participants performed by any of the authors.

\section{References}

Al-Yahyaee, K.H., Rehman, M.U., Mensi, W., Al-Jarrah, I.M.W.: Can uncertainty indices predict Bitcoin prices? A revisited analysis using partial and multivariate wavelet approaches. N. Am. J. Econ. Finance 49, 47-56 (2019)

Arouri, M.H., Jouini, J., Nguyen, D.K.: Volatility spillovers between oil prices and stock sector returns: implications for portfolio management. J. Int. Money Finance 30, 1387-1405 (2011)

Badshah, I.U.: Volatility spillover from the fear index to developed and emerging markets. Emerg. Mark. Financ. Tr. 54, 27-40 (2018)

Baeck, C., Elbeck, M.: Bitcoins as an investment or speculative vehicle? A first look. App. Econ. Lett. 22, 30-34 (2015)

Baillie, R.T., Myers, R.T.: Bivariate garch estimation of the optimal commodity futures Hedge. J. Appl. Econ. 6, 109-124 (1991)

Basher, S.A., Sadorsky, P.: Hedging emerging markets stock prices with oil, gold, VIX, and bonds: a comparison between DCC, ADCC and GO-GARCH. Eng. Econ. 54, 235-247 (2016)

Baur, D.G., Dimpfl, T.: Asymmetric volatility in cryptocurrencies. Econ. Lett. 173, 148-151 (2019)

Baur, D.G., Lee, A.D., Hong, K.: Bitcoin: Currency or Investment? Available at SSRN: 2561183 (2015)

Baur, D., Hong, K., Lee, A.: Bitcoin: Currency or Investment? Senate Economics References Committee Inquiry into Digital Currency, pp. 1-14 (2017)

Ben Cheikh, N., Ben Zaied, Y., Chevallier, J.: Asymmetric volatility in cryptocurrency markets: new evidence from smooth transition GARCH models. Finance Res. Lett. 35, 1-9 (2019)

Bouri, E., Azzi, G., Dyhrberg, A.H.: On the return-volatility relationship in the Bitcoin market around the price crash of 2013. Economics Discussion Papers, No 2016-41, Kiel Institute for the World Economy (2016a)

Bouri, E., Molnár, P., Azzi, G., Roubaud, D., Hagfors, L.I.: On the hedge and safe haven properties of Bitcoin: Is it really more than a diversifier? Finance Res. Lett. 20, 192-198 (2016b)

Bouri, E., Molnár, P., Azzi, G., Roubaud, G., Hagfors, L.I.: On the hedge and safe haven properties of Bitcoin: is it really more than a diversifier? Finance Res. Lett. 20, 192-198 (2017a)

Bouri, E., Gupta, R., Tiwari, A.K., Roubaud, D.: Does Bitcoin hedge global uncertainty? Evidence from wavelet-based quantile-in-quantile regressions. Finance Res. Lett. 23, 87-95 (2017b). https://doi. org/10.1016/j.frl.2017.02.009

Bouri, E., Das, M., Gupta, R., Roubaud, D.: Spillovers between Bitcoin and other assets during bear and bull markets. Appl. Econ. 50, 1-15 (2018). https://doi.org/10.1080/00036846.2018.1488075

Bouri, E., Shahzad, S.J.H., Roubaud, D., Kristoufek, L., Lucey, B.: Bitcoin, gold, and commodities as safe havens for stocks: new insight through wavelet analysis. Q. Rev. Econ. Finance. 77, 56-164 (2020)

Bouri, E., Shahzad, S.J.H., Roubaud, D.: Cryptocurrencies as hedges and safe-havens for US equity sectors. Q. Rev. Econ. Finance 75, 294-307 (2020)

Bouri, E., Lucey, B., Roubaud, D.: Cryptocurrencies and the downside risk in equity investments. Finance Res. Lett. 33, 1-14 (2020c)

Cabera, L.B., Schulz, F.: Volatility linkages between energy and agricultural commodity prices. Eng. Econ. 54, 190-203 (2016) 
Caporale, M.G., Zekokh, T.: Modelling volatility of cryptocurrencies using Markov-Switching GARCH models. Res. Int. Bus. Finance 48, 143-155 (2019)

Cappiello, L., Engle, R.F., Sheppard, K.: Asymmetric dynamics in the correlations of global equity and bond returns. J. Financ. Econ. 4, 537-572 (2006)

Chaim, P., Laurini, M.P.: Volatility and return jumps in Bitcoin. Econ. Lett. 173, 1-15 (2018)

Chan, W.H., Le, M., Wu, Y.W.: Holding Bitcoin longer: the dynamic hedging abilities of Bitcoin. Q. Rev. Econ. Finance. 71, 1-26 (2018)

Conlon, T., Corbet, S., McGee, R.J.: Are cryptocurrencies a safe haven for equity markets? An international perspective from the Covid-19 pandemic. Res. Int. Bus. Finance 54, 1-10 (2020)

Corbet, S., Meegan, A., Larkin, C., Lucey, B., Yarovaya, L.: Exploring the dynamic relationships between cryptocurrencies and other financial assets. Econ. Lett. 165, 1-22 (2018)

Daniel, J.A.: Hedging government oil price risk. IMF Working Paper, WP/01/185 (2001)

Dyhrberg, A.H.: Hedging capabilities of Bitcoin. Is it the virtual gold?. Finance Res. Lett 16, 1-6 (2015)

Dyhrberg, A.H.: Bitcoin, gold and the dollar-a GARCH volatility analysis. Finance Res. Lett 16, 85-92 (2016a)

Dyhrberg, A.H.: Hedging capabilities of Bitcoin. Is it the virtual gold? Finance Res. Lett 16, 139-144 (2016b)

Engle, R.: Dynamic conditional correlation: a simple class of multivariate generalized autoregressive conditional heteroskedasticity models. J. Bus. Econ. Stat. 20(3), 339-350 (2002)

Engle, R., Lee, G.: A permanent and transitory component model of stock return volatility. In: Engle, R.F., White, H.L. (eds.) Cointegration, causality, and forecasting: a festschrift in Honor of Clive W. J. Granger. Oxford University Press, New York (1999)

Fang, L., Bouri, E., Gupta, R., Roubaud, D.: Does global economic uncertainty matter for the volatility and hedging effectiveness of Bitcoin? Int. Rev. Financ. Anal. 16, 1-30 (2018)

Ghabri, Y., Guesmi, K., Zantour, A.: Bitcoin and liquidity risk diversification. Finance Res. Lett. 1-21 (2020) (In press)

Glaser, F., Haferkorn, M., Weber, M., Zimmermann, K.: How to price a digital currency? Empirical insights on the influence of media coverage on the Bitcoin bubble. In: Banking and Information Technology, Vol. 15, Issue 1. Category: Publications in Journals. Reference No.: 2014-2113

Glosten, L., Jagannathan, R., Runkle, D.: Relationship between the expected value and volatility of the nominal excess returns on stocks. J. Finance 48, 1779-1802 (1993)

Ji, Q., Bouri, E., Gupta, R., Roubaus, D.: Network causality structures among Bitcoin and other financial assets: a directed acyclic graph. Q. Rev. Econ. Finance. 70, 1-11 (2018)

Katsiampa, P.: Volatility estimation for Bitcoin: a comparison of GARCH models. Econ. Lett. 158, 3-6 (2017)

Katsiampa, P.: An empirical investigation of volatility dynamics in the cryptocurrency market. Res. Int. Bus. Finance 50, 322-335 (2019)

Kliber, A., Marszałek, P., Musiałkowska, I., Świerczyńska, K.: Bitcoin: safe haven, hedge or diversifier? Perception of Bitcoin in the context of a country's economic situation-A stochastic volatility approach. Physica A Stat. Mech. Appl. 524, 246-257 (2019)

Kristjanpoller, W., Bouri, E.: Asymmetric multifractal cross-correlations between the main world currencies and the main cryptocurrencies. Physica A Stat. Mech. Appl. 523, 1057-1071 (2019)

Kroner, K.F., Sultan, J.: Time dynamic varying distributions and dynamic hedging with foreign currency futures. J. Financ. Quant. Anal. 28, 535-551 (1993)

Pal, D., Mitra, S.K.: Hedging Bitcoin with other financial assets. Finance Res. Lett. 30, 1-14 (2019)

Rehman, M.U.: Do Bitcoin and precious metals do any good together? An extreme dependence and risk spillover analysis. Res. Pol. 68, 1-16 (2020)

Rehman, M.U., Asghar, N., Kang, S.H.: Do Islamic indices provide diversification to Bitcoin? A timevarying copulas and value at risk application. Pac. Bas. J. 61, 1-26 (2020)

Selgin, G.: Synthetic commodity money. J. Financ. Stab. 17, 92-99 (2015)

Selmi, R., Hammoudeh, S., Bouoiyour, J.: Is Bitcoin a hedge, a safe haven or a diversifier for oil price movements? A comparison with gold. Energy Econ. 74, 787-801 (2018)

Shahzad, S.J.H., Bouri, E., Roubaud, D., Kristoufek, L., Lucey, B.: Is Bitcoin a better safe-haven investment than gold and commodities? Int. Rev. Financ. Anal. 63, 322-330 (2019)

Su, C.-W., Qin, M., Tao, R., Shao, X.-F., Albu, L.L., Umar, M.: Can Bitcoin hedge the risks of geopolitical events? Technol. Forecast. Soc. Change 159, 1-9 (2020)

Urquhart, A., Zhang, H.: Is Bitcoin a hedge or safe haven for currencies? An intraday analysis. Int. Rev. Financ. Anal. 63, 49-57 (2019) 
Wang, Y., Wu, C.: Forecasting energy market volatility using GARCH models: can multivariate models beat univariate models? Eng. Econ. 34, 2167-2181 (2012)

Wang, G., Tang, Y., Xie, C., Chen, S.: Is Bitcoin a safe haven or a hedging asset? Evidence from China. J. Manag. Sci. Eng. 4, 173-188 (2019)

Yermack, D.: Is Bitcoin a Real Currency? An Economic Appraisal. NBER Working Paper (2013)

Zhou, J., Nicholson, J.R.: Economic value of modeling covariance asymmetry for mixed-asset portfolio diversifications. Econ. Model. 45, 14-21 (2015)

Publisher's Note Springer Nature remains neutral with regard to jurisdictional claims in published maps and institutional affiliations. 